\title{
Analytical Survey for Assuring Quality Standards in GPS based Tracking System
}

\author{
Sana Bibi \\ Fatima Jinnah Women \\ University \\ The Mall, Rawalpindi \\ Pakistan
}

\author{
Umber Nazir \\ Fatima Jinnah Women \\ University \\ The Mall, Rawalpindi \\ Pakistan
}

\author{
Mehreen Sishar \\ Fatima Jinnah Women \\ University \\ The Mall, Rawalpindi \\ Pakistan
}

\begin{abstract}
In today's fast moving life GPS based tracking system has very much importance in everyone's life where loved ones, vehicles, mobile phones and other devices can be located with a touch of a button. Different quality parameters that are followed in GPS tracking systems are reported in this literature that helps in improving the quality of the tracking systems. This research paper is the survey based analysis of how GPS based tracking systems assures their quality in different applications. After analysis of the quality parameters, it has been explored that most of the GPS based tracking system are user friendly, cost effective, reliable and can be easily validated through different experiments and simulations. Most of the techniques are used for security and safety purpose but they lack reusability factor. In future, we can work on the reusability of different techniques.
\end{abstract}

\section{General Terms}

GPS tracking System, Encryption, Real Time Positioning

\section{Keywords}

GPS-GPRS, GPS Tracking System, GPS-GSM, tracking System,

\section{INTRODUCTION}

The Global Positioning System (GPS) is made conceivable by a gathering of satellites in a circle around the earth orbit that transmit exact signs, permitting GPS receivers to manipulate and show the exact location, speed, and time information to the user.

By catching the signals from three or more satellites (among a group of 31 satellites), GPS receivers have the ability to fully utilize the guideline of trilateration to pinpoint a location. With the evolution in processing power, and information fed into the memory, for example, points of interest, road guides, topographic data, and many more, GPS receivers have the ability to change the location, speed, and time data into a helpful display design. GPS information might likewise be fed to a website for real-time location mapping.

GPS tracking takes the ordinary functions of a GPS device a step further, by either catching or storing position information inside the internal memory for retrieval later, or by transmitting location information continuously through the same cell information system utilized by cellular telephones. All techniques we have surveyed uses GPS and GPRS through GSM networks to make the system cheap and accessible all over the world. For the enhancing the interactivity most systems are integrated with websites as well as with mobile phones.
When GPS tracking comes to the business, it can make a serious advantage either in monitoring the employees or keeping track of shipped cargo.

GPS tracking can be a significant cost-effective tool for all small or large sized business. If there are a fleet of vehicles, GPS tracking may have the ability to help the fleet decrease leisure times, enhance directing operations, and better customer service. As a result, it may be able to lower overhead business costs and increase bottom line. Further in this research paper summary, analysis, parameters and conclusion will be discussed.

\section{TECHNIQUES SURVEYED FOR QUALITY ASSURANCE}

Global positioning satellites network is known to have offered users a number of services and application especially in the field of tracking. It can also be used in tracking the distance travelled on a trip, vehicle mileage, and speed. [1]

Due to the increasing need of vehicle tracking, many systems have been proposed, designed and implemented. This section discusses some of the basic features that previous systems provided. [6]

\subsection{Design and Development of a Low Cost Ubiquitous Tracking System (M. Behzad et al., 2014)}

This paper presents a GPS and GSM based vehicle tracking system that provides the owner of a mobile asset with full security and track of the asset. To track any vehicle, the owner has to send an SMS to the system installed inside the vehicle. The microcontroller takes the current location from GPS, upon receiving the SMS, and sends it to the owner using GSM. The owner of the asset can find the status of the vehicle and control to turn its engine off with just an SMS, this service is available 24/7. The only owner can access the website and use android app to communicate with their vehicles. This system is specially designed to overcome the problems of traffic organization, vehicle theft and surveillance. The system does not provide user with an independent tracking system because it uses GPRS and SMS gateways. It fails if the SMS gateway and GPRS is blocked, so, it is totally dependent. The limited and portable battery power is a bottleneck in WSNs. Hence, this can't be utilized for long haul, standalone and dependable following framework. Above all, the cost of this system is much less comparatively, which makes it economical. The system design turns out to be the most efficient, robust and powerful tracking system design with a number of features to offer. It can be easily installed in any vehicle to check status with just an SMS. 


\subsection{Real-Time Tracking Management System Using GPS, GPRS and Google Earth (Noppadol Chadil et al., 2008)}

The paper proposed a real-time tracking management system named goo-Tracking, which is composed of hardware (GPS/GPRS device), open source software (web server), and user interface (Google Map or Google Earth). The GPS device is an embedded system (in vehicles) that transmits location information to the server through GPRS networks, and then the server receives the information and put it in the database, which formats it in a form that can search and display using Google Earth or Google Map. The system performs three stages, the initialization, the GPS position determining, and the GPS data formatted and transmitted to Goo-tracking server via GPRS networks. As the system used GPS and GPRS networks, this makes it low cost and easily accessible worldwide. But also it is dependent and cannot standalone. This system is feasible for fleet Management Systems (FMS). It can also be used for lost vehicle tracking.

\subsection{An application of $\mathrm{V} 2 \mathrm{~V}$ communications: Cooperation of vehicles for a better car tracking using GPS and Vision systems (Georges Chalita et al., 2009)}

In this paper, characteristics and errors of GPS data, communication systems, the monovision systems and the particle filters used to track the vehicle are discussed. To overcome different errors occur in GPS data, Vision System is proposed. The Vision System in the prototype vehicle, used for this application is equipped with digital color cameras and vision-based vehicle's rear detection system. The proposed system is expensive and only designed for urban areas or fleet management systems. The benefits are shown on an urban transport network scenario, which proves the stability of the method and the contribution of the vision in the vehicle positioning accuracy whenever the GPS is unavailable. This method can be applied to the accurate location of different vehicle fleets in urban areas like people transportation or (high-value) goods transportation where the positioning information will be known accurately and continuously (traveler information systems, security systems etc.).

\subsection{Design and Implementation of the Low- Power Tracking System Based on GPS- GPRS Module (Peng Wang et al., 2010)}

The purpose of this paper is to develop a low-power Tracking system using GPS/GPRS, which can provide needs of security, to track the location of mobile devices. The GPS/GPRS modules receive messages from GPS satellites, and then indicate due to different states. The information gathered in a control center where the software is running to analyze indication and then return latitude and longitude which can easily viewed on a Google Map. The main focus in this system is to decrease energy consumption and increase life-time. For this many hardware and software are used in this system, which makes it complex and expensive. This system is usually used in large projects as its GPRS network architecture is too wide.

\subsection{Ruggedisation Methodologies for GPS based Vehicle Tracking System \\ (M.S.Sutaon et al., 2011)}

The purpose of this paper is to develop a ruggedized GPS based Vehicle Tracking System (VTS). For this system is subjected to several tests according to different standards. Tests include Environmental, Dynamic, Corrosion, Susceptibility, ESS and Burn-in etc. Furthermore the effects of these tests on the equipment leading to probable damage/failure in the system taken in account for reliability of equipment to make it compatible in extreme conditions are discussed in this paper. Integrated approach is used for evolving the methods of Ruggedisation. The results found are satisfactory after using standardized equipments and compatible in severe environment. To make the system ruggedized a lot of testing required on the components. All the methods implemented and the ruggedized equipments used (after testing) are expensive. Its applications are found in stringent and extreme environments.

\subsection{Finite Element Analysis of GPS Based Vehicle Tracking System with Enclosure for Dynamic Assessment (Iman M. Almomani et al., 2011)}

In this paper the vibration effects on GPS based vehicle tracking system (VTS) is introduced to be used in extreme environment. The failures due to vibration and benefits of the vibration test methods are also discussed in this paper. ANSYS software is used in the GPS based VTS which uses the Finite Element Analysis to simulate the natural frequencies and the stress level (with/without shock mounts). Through simulation the stress levels compared with UTS (Ultimate Tensile Strength) to find out sustainable applied vibrations. No mechanical damage of any kind was observed in the system. Hence, HE-30 Enclosure meets the compatibility requirements with JSS-55555 / MIL 810E standards for vibration specifications. The application of this system is found in Military based Tracking Systems.

\subsection{Ubiquitous GPS Vehicle Tracking and Management System (Shreenivas Jog et al., 2012)}

In this paper GPS based Vehicle Tracking System is proposed. The main purpose of this paper is two types of end user applications; web and mobile application. This system uses GPS, GSM, GPRS and the Internet or the World Wide Web. The system allows the user to track their vehicles position, speed, stops and movements through web application (Internet) and by receiving SMS (GPRS), by providing ubiquitous access anytime anywhere. According to the setting speed and geographical limits this system can monitor the vehicle by receiving SMS alerts when exceeds these predefined limits. This system is applied in fleet operators in monitoring driving behavior, parents monitoring their teen drivers and car theft by combining device with the car alarm.

\subsection{Simplified Low-Cost GPS-Based Tracking System for Soccer Practice \\ (Pattarakamon Rangsee et al., 2013)}

In this paper Football Player Tracking System (FPTS) is designed based on GPS. This low-cost GPS module is used to detect position of players during game. This system is divided into two parts, a mobile part and the ground part. Mobile part is attached to the wrist pad of the player, by which position is detected and sends data through Xbee (wireless technology).Ground part, located in the centre of the field, process the data from mobile part, calculate and display the speed, distance, route of each football player and save the data into the database. It is portable and can be used in any field. 
FPTS can compensate the error of position occurred in GPS. The FPTS helps the football team in rural areas which does not have the professional couch. This system is applied to any sports field that is square in shape.

\subsection{GPS and Ethernet based Real Time Train Tracking System (R.Immanuel Rajkumar et al., 2013)}

In this paper a tracking system is proposed for train safety by using GPS and communication of information through Ethernet. The system communicates the real time information about the train position and the health status by using different sensors integrated in the train. Along with GPS and Ethernet, Arduino (microcontroller) is also used which provides complete capability for this computations. The locations of vehicle are mapped using their IP addresses in the Google map, where each point is indicating the vehicle along with information about the train and the driver alcohol status, max speed, and co-ordinates etc. The location from the train send to the controller end where it can be seen on the map and displayed on html based window. In this way the user at remote place can monitor complete details of the train by sharing the same network server. The same system can be implemented to any vehicle i.e. Car, Truck, Van, Bus etc.

\subsection{Cost Effective GPS-GPRS Based Object Tracking System (Mashiur Rehman et al., 2009)}

In this paper GPS based Vehicle Tracking System is proposed. The main purpose of this paper is two types of end user applications; web and mobile application. This system uses GPS, GSM, GPRS and the Internet or the World Wide Web. The system allows the user to track their vehicles position, speed, stops and movements through web application (Internet) and by receiving SMS (GPRS), by providing ubiquitous access anytime anywhere. According to the setting speed and geographical limits this system can monitor the vehicle by receiving SMS alerts when exceeds these predefined limits. This system is applied in fleet operators in monitoring driving behavior, parents monitoring their teen drivers and car theft by combining device with the car alarm.

\subsection{Mobile Tracking Application for Locating Friends Using LBS \\ (A.Takewade et al., 2013)}

In this paper the author plans to implement and design a client server system to spot their friends and family members using cellular phones. The user can be directed towards his/her destination by utilizing this application. The principal objective of this research is to make the GPS systems more accurate and to minimize position errors. The methodology used in this research paper is the case study and literature review. The main advantage of this system is that it gives security to the ladies specially and gives hostile to burglary by sending GPS data to the nearest police headquarters. This system has some privacy issues as LBS create definite record that may uncover personal and individual certainties around an individual's life. This system can be used to in providing emergency services to women all around the world.

\subsection{The Integration of GPS Navigator Device with Vehicles Tracking System for Rental Car Firms (O.O.Alharaki et al., 2010)}

In this paper the author has proposed a new vehicle tracking system for the rental cars to manage and track the cars by integrating GPS technology with GPS navigation system. This system provides communication between rental firms and the customer and it also provide information about the car like its location, speed, fuel etc. The methodology used in this paper is case study and literature review. This system has given many benefits to the rental firms and customers also as they can easily track their car in case of theft or robbery or delay in car return. Its implementation is very simple and saves firm's time and money. This system can be also be used in different show rooms for car's safety and also in personal cars.

\subsection{Design and Development of GPS-GSM based Tracking System with Google Map Based Monitoring (P.Verma et al., 2013)}

In this research paper the author has illustrates how we can make our vehicles safe and secure by using GPS - GSM technology and web application. The vehicle can be spotted utilizing GPS reception apparatus and GSM gives transmission and accepting of information. Web application in Google Map gave the complete yield of the framework and figures the separation between two focuses gave by the GPS framework.. This research is based on literature review and case studies. This system is easy to install, easy to use and access and it works in any weather condition. This system can be used to track animals in zoo, in delivery services, in cop department and fire services and to look after the children. The most important aspect of this system is its scalability as this system provide platform to make further enhancements.

\subsection{GPS Tracking Simulation by Path}

\section{Replaying (G.Rajendran et al., 2011)}

This paper discusses the GPS tracking simulation process to generate the database of GPS tracking data so that the researchers can use it. The process includes three steps. That are, generating log files from GPA receiver for each path, then refining those $\log$ files and finally replaying those files to produce simulation. The information produced in this process can be utilized by analysts to create and test GPS applications.. This generator can likewise be utilized by programming designers and the fledgling clients of GPS to learn route programming. At present this framework recreates an altered number of vehicles at first set amid the execution. In future, this work can be stretched out to recreate arbitrary number of moving vehicles anytime of time.

\subsection{GPS and GPRS Based Passenger}

Tracking System (Dalip et al., 2014)

In this research paper the author has introduced a real time GPS-GSM based passenger tracking system. This system uses ticket number of the passenger to track and display his/her location on Google map. This research is based on both experiments and literature review. The proposed system has minimized the cost as the current tracking system was based on RFID (Radio Frequency Identification) which was exceptionally expensive. This system also supports both mobile and web application to make it accessible anywhere and anytime. This schema can be used inside fleet, squad cars 
and auto thievery alarms. The limitation of this system is that it only works when the user enters the passenger's ticket number. This system is scalable to make further enhancements.

\subsection{GPS Tracking and Controller for Car Black Box on FPGA (B.Pournima et al., 2013)}

In this paper the author proposes the design of Black Box controller in cars using GPS tracking system. The GPS system is incorporated in the Car Black Box in order to locate the car at anyplace. The main purpose of designing a black box for car is to analyze the road accidents easily and to settle disputes related to the accidents. The research methodology used in this research is experiments. The main feature of this system is its usability alongside the small size and visual presentation of results utilizing PC and LCD display. All interfacing is carried out utilizing serial correspondence. The main advantage of this system is that it enhances vehicle plan, roadway outline and doctor's services. Also it sends mishap location data to calamity server progressively so that the drivers who need help can get benefit rapidly by rack auto, police and doctor's facility emergency vehicle.

\subsection{Reconfigurable hardware implementation of a GPS based Vehicle Tracking System (A.Yakzan et al., 2008)} In this research paper the author has discussed an alternative design and implementation of the GPS based vehicle tracking system by using reconfigurable systems instead of microcontroller based systems. This research is based on experiments. An ARAM locator GPS system comprises of two microcontrollers which are then replaced by hardware entity controlled by I2C having 2 processes. FPGA system's implementation is then tested and found more flexible and vulnerable to changes. It has boosted up the performance and speed with minimal cost. But the drawback of this system was that the processes are not parallel rather they are sequential and also it has small memory. This framework can be used locate the vehicle position.

\subsection{Low-Cost Mobile Tracking Solution \\ (R.K.Moloo et al., 2011)}

In this research paper the author had suggested a low cost mobile GPS tracking system. The proposed system permits a user to view real time positioning and recorded tracks of a cell telephone adjusted for the system. A web application has been delivered using PHP and MySql and the free manifestation of Google Maps. The framework reaches its target of being ease and is indeed the least expensive framework created with numerous functionalities of all current following systems researched. The methodology used in this research is literature view. The main advantage of this system is its lowest cost and the limitation of this system is that this application can only be used in cell phones having MDP and WAP and it consumes a lot of battery. This system can be used in fleet management and family monitoring.

\subsection{A Secure Tracking System for GPS Enabled Mobile Phones (Bilgic et al., 2011)}

This paper discusses the secure tracking system for GPS enabled cell phones that include web interface, geo-fencing and encryption. The web application is connected with mobile clients. The user monitors the tracking locations of the person or party using that mobile application.. This research strategy utilized for this system is experimentation and testing. The proposed system improves the usability for mobile clients to be tracked more closely and carefully. This system can be used in different companies to track their employees' location and also by the parents to look after their children. This framework has been tried with a lot of clients and utilizing diverse models of cellular telephones. A Network simulation is recommended for the future to test the execution of the system with as many clients as possible.

\subsection{An Analysis of Crime Hot Spot using GPS Tracking Data of Children and Agent Based Simulation Modeling} (Kikuchi, G., et al., 2012)

In this paper the author has focused on child exploitation and to investigate the crime hot spots, he has examined three sub studies. First sub study includes obtaining GPS tracking data of 80 students for 2 weeks. In second sub study simulation modeling is used to determine the population at danger and in third sub study, exploitation survey has been conducted and the results of the survey is utilized alongside the result of first two sub studies, to determine the crime hot spots. It can be used to keep children distinctive from different culprits and wrongdoers. We can stop child abuse using GPS System and simulation modeling. The drawback of the proposed system is that it is only useful for children, and not for adults. This system can be utilized as a part of observing frameworks to identify the culprits and unauthorized activities and also it can be used to enforce strict laws at areas having more crime incidents.

\section{ANALYSIS}

Table 2 and Table 3 show the results of analysis of evaluation parameters evaluation criteria defined in table 1. 20 techniques have been surveyed on GPS based tracking system and eighteen parameters have been used in the evaluation of these techniques. Different quality assurance techniques are used to assure the quality in GPS tracking System. Functionality is the parameter that is followed in all the twenty techniques as the GPS Systems can be operates perfectly according the specified requirements. None of the techniques has discussed the reusability of the GPS tracking system. Therefore, reusability is the limitation of these techniques.

Table 2 and Table 3 reveal that all techniques show good performance except A.Yakzan et al. [17] and Iman M. Almsman et al [6]. Real time systems are time critical systems therefore; all techniques have been designed keeping in view to handle timing constraints as efficiently as possible except P.Verma et al [13] and A.S.Nookabdi et al [20]. Except Iman M. Almomani et al [6], G.Rajendran et al [14], and A.Yakzan et al [17], all techniques used tracking mechanism for safety purpose. Iman M. Almomani et al [6], Shreenivas Jog et al [7], Mashiur Rahman et al [10], B.Pournima et al [16], and P.Verma et al [13] follow robustness by showing great stability and robust message transfer protocol, while rest of the techniques do not have this quality parameter. All techniques can be formally validated except Pattarakamon Rangsee et al [8] O.O.Alharaki et al [12], Dalip et al [15] and B.Pournima et al [16] which do not show any concern about validation .In some techniques simulation method is used for validation purpose. Only few techniques B.Pournima et al [16], M.S.Sutaon et al [5], Iman M. Almomani et al [6], Shreenivas Jog et al [7], Pattarakamon Rangsee et al [8], Georges Challita et al [4] and R.Immanuel Rajkumar et al [9] 
are verified through experimentation and different types of testing while the rest are not verifiable. Most of the techniques are simpler and easy to use so that they can be used by nontechnical audience but Shreenivas Jog et al [7], A.Takewade et al [11], Dalip et al [15], A.Yakzan et al [17], and A.S.Nookabdi et al [20] do not follow ease of usability. Almost half of the techniques surveyed are easy to maintain and provide accurate data while the rest half of the techniques have low maintainability. As far as privacy is concerned, all techniques provide security of personal data except Iman M. Almomani et al [6] and A.Takewade et al [11]. Noppadol Chadil et al [2], Peng Wang et al [4], Iman M. Almomani et al
[6], and P.Verma et al [13] are effective techniques by getting successful results on several testing while other techniques does not discussed about effectiveness.

Analysis shows that half techniques are reliable on the basis of equipments, devices and accuracy of time and position. Half techniques have the ability to be scalable, to add new techniques/components while other does not show this property. Similarly, during analysis we observed that cost effectiveness is also not found in all techniques. Some techniques are cost effective they use low cost technology and GSM modem for networking.

Table 1 Evaluation Criteria for Quality Assurance Standards

\begin{tabular}{|c|c|c|}
\hline $\begin{array}{l}\text { Quality Assurance } \\
\text { Parameters }\end{array}$ & Definitions & Possible Values \\
\hline Interoperability & Machine Independence. & Yes/No \\
\hline Robustness & $\begin{array}{c}\text { The ability of a computer system to cope with errors and } \\
\text { failures. }\end{array}$ & Yes/No \\
\hline Portability & Platform Independence. & Yes/No \\
\hline Compatibility & $\begin{array}{c}\text { Ability of the elements of software to combine easily with } \\
\text { other elements. }\end{array}$ & Yes/No \\
\hline Extendibility & Ability of a system to adapt new features. & Yes/No \\
\hline Efficiency & $\begin{array}{c}\text { Ability of a system to perform efficient in terms of time, } \\
\text { speed and resources. }\end{array}$ & Yes/No \\
\hline Verification & $\begin{array}{l}\text { Confirmation by examining and providing objective evidence } \\
\text { that specified requirements have been fulfilled. }\end{array}$ & Yes/No \\
\hline Integrity & $\begin{array}{c}\text { Ensuring that data is real, accurate and safeguarded from } \\
\text { unauthorized user modification. }\end{array}$ & Yes/No \\
\hline Ease of Use & User-friendly & Yes/No \\
\hline Maintainability & How easy the system is to maintain & Yes/No \\
\hline Performance & How well a system performs in terms of responsiveness & Yes/No \\
\hline Cost Effectiveness & $\begin{array}{l}\text { Ability to produce good results without costing a lot of } \\
\text { money }\end{array}$ & Yes/No \\
\hline Scalability & $\begin{array}{c}\text { Ability of to continue functionality as it changes its size or } \\
\text { volume }\end{array}$ & Yes/No \\
\hline Security & $\begin{array}{c}\text { Ability to check whether the application is vulnerable to } \\
\text { attacks. }\end{array}$ & Yes/No \\
\hline Validation & How easy to test & Yes/No \\
\hline Safety & Ensuring safe operations for any system. & Yes/No \\
\hline Reliability & $\begin{array}{c}\text { How well the system performs in its claim time and in a } \\
\text { particular environment }\end{array}$ & Yes/No \\
\hline Effectiveness & How much successful the system is & Yes/No \\
\hline
\end{tabular}


Table 2 Analysis of Quality Assurance Standards Parameter-I

\begin{tabular}{|c|c|c|c|c|c|c|c|c|c|c|c|c|c|c|c|c|c|c|c|}
\hline$\frac{\dot{0}}{\dot{z}}$ & & 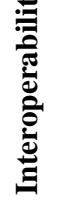 & 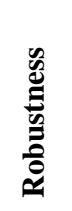 & 竞 & 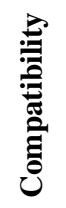 & 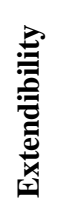 & : & : & 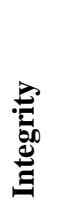 & 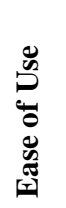 & 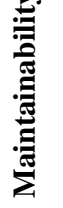 & 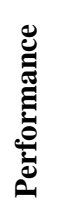 & 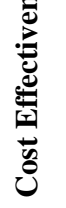 & 莺 & 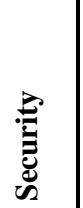 & : & $\frac{\overrightarrow{0}}{\stackrel{0}{0}}$ & 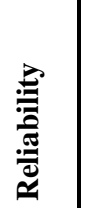 & 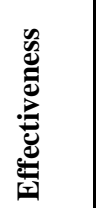 \\
\hline 1 & $\begin{array}{l}\text { M. Behzad et al. } \\
2014\end{array}$ & Yes & Yes & Yes & No & Yes & Yes & No & Yes & Yes & No & Yes & Yes & Yes & Yes & Yes & No & Yes & Yes \\
\hline 2 & $\begin{array}{l}\text { Noppadol Chadi } \\
\text { et al., } 2008\end{array}$ & Yes & No & No & Yes & Yes & Yes & No & Yes & Yes & No & Yes & Yes & Yes & Yes & Yes & Yes & No & No \\
\hline 3 & $\begin{array}{l}\text { Georges Challita } \\
\text { et al., } 2009\end{array}$ & NA & No & Yes & No & Yes & Yes & Yes & Yes & Yes & Yes & Yes & No & No & Yes & Yes & Yes & Yes & Yes \\
\hline 4 & $\begin{array}{l}\text { Peng Wang et al } \\
2010\end{array}$ & Yes & No & Yes & Yes & Yes & Yes & No & Yes & Yes & Yes & Yes & Yes & Yes & Yes & Yes & No & No & No \\
\hline 5 & $\begin{array}{l}\text { M.S.Sutaon et } \\
\text { al.,2011 }\end{array}$ & No & No & Yes & Yes & Yes & Yes & Yes & Yes & Yes & NA & Yes & No & Yes & Yes & Yes & Yes & Yes & Yes \\
\hline 6 & $\begin{array}{l}\text { Iman M. } \\
\text { Almomani et al. } \\
2011\end{array}$ & Yes & Yes & No & No & Yes & Yes & Yes & Yes & Yes & Yes & No & No & No & No & Yes & No & No & No \\
\hline 7 & $\begin{array}{l}\text { Shreenivas Jog } \\
\text { al., } 2012\end{array}$ & NA & Yes & NA & Yes & No & Yes & Yes & NA & No & No & Yes & Yes & No & Yes & Yes & No & Yes & Yes \\
\hline 8 & $\begin{array}{l}\text { Pattarakamon } \\
\text { Rangsee et al., } \\
2013\end{array}$ & No & No & Yes & No & Yes & Yes & Yes & No & Yes & Yes & Yes & Yes & No & Yes & No & No & Yes & Yes \\
\hline 9 & $\begin{array}{l}\text { R.Immanuel } \\
\text { Rajkumar et al., } \\
2013\end{array}$ & No & No & No & Yes & No & Yes & Yes & No & Yes & No & Yes & No & Yes & Yes & Yes & Yes & Yes & Yes \\
\hline 10 & $\begin{array}{l}\text { Mashiur Rahma } \\
\text { et al., } 2009\end{array}$ & Yes & Yes & No & No & Yes & Yes & No & No & Yes & No & Yes & Yes & No & Yes & Yes & Yes & Yes & Yes \\
\hline
\end{tabular}

Table 2 Analysis of Quality Assurance Standards Parameter-II

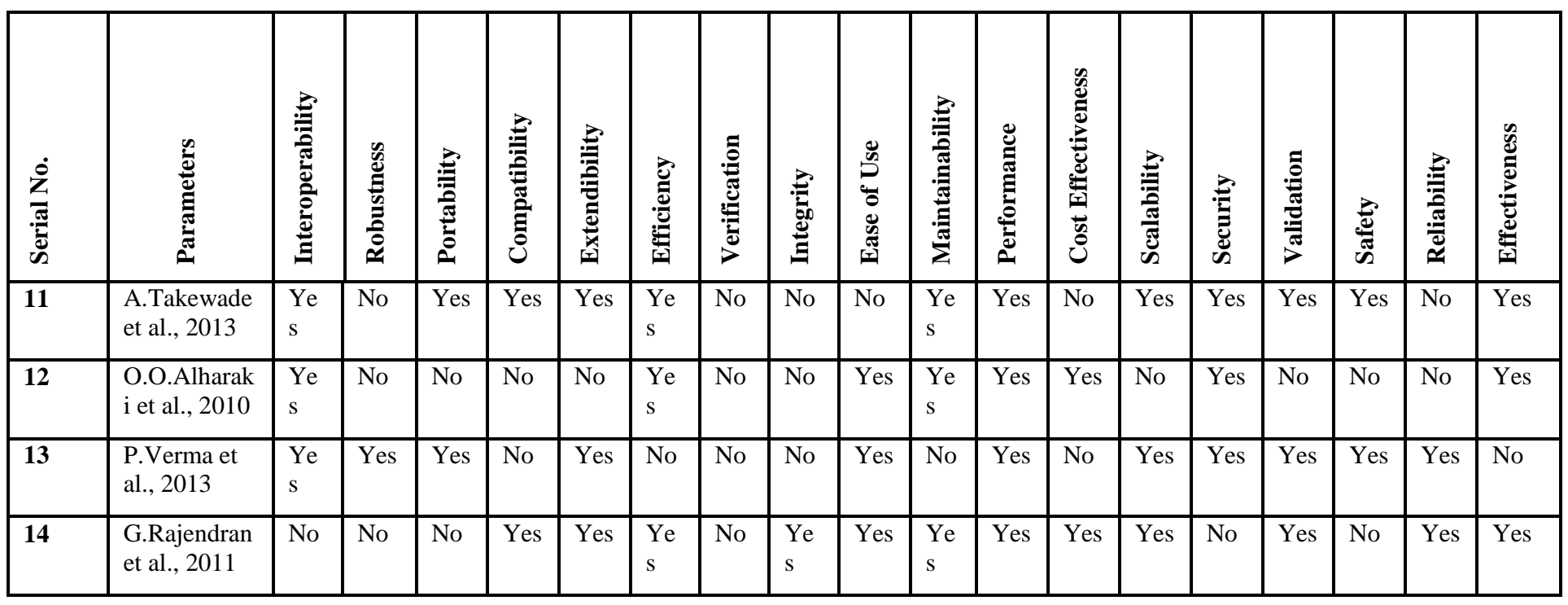




\begin{tabular}{|c|c|c|c|c|c|c|c|c|c|c|c|c|c|c|c|c|c|c|c|}
\hline 15 & $\begin{array}{l}\text { Dalip et al., } \\
2014\end{array}$ & No & No & Yes & Yes & Yes & $\begin{array}{l}\text { Ye } \\
\mathrm{s}\end{array}$ & No & No & No & No & Yes & Yes & Yes & Yes & No & Yes & No & Yes \\
\hline 16 & $\begin{array}{l}\text { B.Pournima } \\
\text { et al., } 2013\end{array}$ & $\begin{array}{l}\text { Ye } \\
\text { s }\end{array}$ & Yes & Yes & Yes & No & $\begin{array}{l}\mathrm{Ye} \\
\mathrm{s}\end{array}$ & $\begin{array}{l}\mathrm{Ye} \\
\mathrm{s}\end{array}$ & No & Yes & No & Yes & No & No & Yes & No & Yes & Yes & Yes \\
\hline 17 & $\begin{array}{l}\text { A.Yakzan et } \\
\text { al., } 2008\end{array}$ & No & No & Yes & Yes & Yes & $\begin{array}{l}\text { Ye } \\
\mathrm{s}\end{array}$ & No & No & No & $\begin{array}{l}\mathrm{Ye} \\
\mathrm{s}\end{array}$ & No & Yes & Yes & No & Yes & No & Yes & Yes \\
\hline 18 & $\begin{array}{l}\text { R.K.Moloo } \\
\text { et al., } 2011\end{array}$ & $\begin{array}{l}\text { Ye } \\
\text { s }\end{array}$ & No & Yes & Yes & No & $\begin{array}{l}\text { Ye } \\
\mathrm{s}\end{array}$ & No & $\begin{array}{l}\text { Ye } \\
\mathrm{s}\end{array}$ & Yes & $\begin{array}{l}\mathrm{Ye} \\
\mathrm{s}\end{array}$ & Yes & Yes & No & Yes & Yes & Yes & No & Yes \\
\hline 19 & $\begin{array}{l}\text { Bilgic et al., } \\
2011\end{array}$ & $\begin{array}{l}\mathrm{Ye} \\
\mathrm{s}\end{array}$ & No & Yes & Yes & No & $\begin{array}{l}\mathrm{Ye} \\
\mathrm{s}\end{array}$ & No & $\begin{array}{l}\mathrm{Ye} \\
\mathrm{s}\end{array}$ & Yes & $\begin{array}{l}\mathrm{Ye} \\
\mathrm{s}\end{array}$ & Yes & No & Yes & Yes & Yes & No & No & Yes \\
\hline 20 & $\begin{array}{l}\text { A.S.Nookab } \\
\text { di et al., } \\
2011\end{array}$ & $\begin{array}{l}\text { Ye } \\
\mathrm{s}\end{array}$ & No & Yes & Yes & Yes & No & No & $\begin{array}{l}\mathrm{Ye} \\
\mathrm{s}\end{array}$ & No & No & Yes & No & No & Yes & Yes & Yes & No & Yes \\
\hline
\end{tabular}

\section{CONCLUSION}

In this research paper, quality assurance standards considered which are followed by different techniques used in systems in the surveyed papers. Upon quality standards these techniques are adopted to achieve Quality in their processes. Mainly in our survey all the techniques and methodologies used to provide secure, robust and low cost systems for the owners to satisfy their needs for tracking through GPS and GPRS of GSM network. Most of the systems used GSM network for the sending messages as it is the cheapest way to send SMS as compared to other modes of communication. Along with GSM technique, systems used web services to facilitate their users with the help of interactive web pages. Some systems follow the quality standards to improve their work with the growing need of security and accuracy in the services but some are unable to compete with them in this quality standard. Now days, achieving quality is very important to compete with others in this growing technological world to uphold your work in international market and to fulfill the customer requirements. For future work, more services could be added to the mobile application, make it more fast and accurate, and also the graphical user interface could be improved in these systems to make it more interactive for the users.

\section{REFERENCES}

[1] Behzad, M., A. Sana, M. A. Khan, Z. Walayat, U. Qasim, Z. A. Khan, and N. Javaid, 2014 Design and Development of a Low Cost Ubiquitous Tracking System

[2] Chadil N., A. Russameesawang, and P. Keeratiwintakorn,2008 Real-time tracking management system using GPS, GPRS and Google earth.

[3] Challita, Georges, Stéphane Mousset, Fawzi Nashashibi, and Abdelaziz Bensrhair, 2009 An application of V2V communications: Cooperation of vehicles for a better car tracking using GPS and vision systems

[4] Wang, P., Zhao, Z., Xu, C., Wu, Z., and Luo, Y., 2010 Design and implementation of the low-power tracking system based on GPS-GPRS module.

[5] Jog, S. R., Sutaone, M. S., and Badawe, V. 2011 V, Ruggedisation methodologies for GPS based Vehicle Tracking System

[6] Almomani, Iman M., Nour Y. Alkhalil, Enas M. Ahmad, and Rania M. Jodeh, 2011 Ubiquitous GPS vehicle tracking and management system
[7] Jog, S., P. Gupta, M. Sutaone, V. V. Badawe, A. Kumar, S. Gade, and K. Deshpande, 2012 Finite element analysis of GPS based vehicle tracking system with enclosure for dynamic assessment

[8] Rangsee, P., Suebsombat, P., \& Boonyanant, P., 2013 Simplified low-cost GPS-based tracking system for soccer practice

[9] Rajkumar, R. I., Sankaranarayanan, P. E., \& Sundari, G., GPS and Ethernet based real time train tracking system

[10] Hasan, K. S., Rahman, M., Haque, A. L., Rahman, M. A., Rahman, T., \& Rasheed, M. M. 2009 Cost effective GPS-GPRS based object tracking system,

[11] Tekawade, A., Tutake, A., Shinde, R., Dhole, P., \& Hirve, M. S., 2013 Mobile Tracking Application for Locating Friends using LBS,

[12] Alharaki, O. O., Alfieri, F. S., \& Saki, A. M., 2008 The Integration of GPS Navigator Device with Vehicles Tracking System for Rental Cars Firms

[13] Verma, P., \& Bhatia, J. S., 2013 Design and Development of GPS-GSM based Tracking System with Google Map based Monitoring, International Journal of Computer Science

[14] Rajendran, G., Arthanari, M., \& Sivakumar, M., 2011 GPS Tracking Simulation by Path Replaying

[15] Dalip and Vijay Kumar, 2014 GPS and GSM based Passenger Tracking System

[16] Ms. Bhalerao Pournima and Prof V. B. Baru, 2013 GPS Tracking and Controller for Car Black Box on Fpga

[17] Yaqzan, A., Damaj, I., and Zantout, R., 2009 Reconfigurable Hardware Implementation of a GPSBased Vehicle Tracking System

[18] Moloo, R. K., \& Digumber, V. K., 2011 Low-cost mobile GPS tracking solution

[19] Bilgic, H. T., \& Alkar, A. Z., 2011 A secure tracking system for GPS-enabled mobile phones

[20] Kikuchi, G., Amemiya, M., and Shimada, T. 2012 An analysis of crime hot spots using GPS tracking data of children and agent-based simulation modeling

[21] Maria Khalid, Isma Yakoob, Farhana Shahid, Rohma Nayab and Mehreen Sirshar, 2013 Quality Assurance Standards and Survey of IT Industries

[22] Sirshar, M., 2012 Evaluation of Quality Assurance Factors in Agile Methodologies. 